\title{
Synergistic effect of polymorphisms of paraoxonase gene cluster and arsenic exposure on electrocardiogram abnormality
}

\author{
Ya-Tang Liao ${ }^{\text {a,b }}$, Wan-Fen Li ${ }^{\text {a }}$, Chien-Jen Chen ${ }^{\text {b,c }}$, Ronald J. Prineas ${ }^{\text {d }}$, Wei J. Chen ${ }^{\text {b,e }}$, Zhu-Ming Zhang ${ }^{\text {, }}$ \\ Chien-Wen Sun ${ }^{\text {a }}$, Shu-Li Wang ${ }^{\text {a,f,* }}$ \\ a Division of Environmental Health and Occupational Medicine, National Health Research Institutes, Taiwan \\ b Graduate Institute of Epidemiology, College of Public Health, National Taiwan University, Taiwan \\ c Genomics Research Center, Academia Sinica, Taiwan \\ d Epidemiologic Cardiology Research Center, Department of Epidemiology and Prevention, Division of Public Health Sciences, Wake Forest University School of Medicine, NC, USA \\ e Genetic Epidemiology Core Laboratory, National Taiwan University Center for Genomic Medicine, Taiwan \\ ${ }^{\mathrm{f}}$ Institute of Environmental Medicine, College of Public Health, China Medical University Hospital, Taichung, Taiwan
}

\section{A R T I C L E I N F O}

\section{Article history:}

Received 15 September 2008

Revised 7 December 2008

Accepted 12 December 2008

Available online $\mathrm{xxxx}$

\section{Keywords:}

Arsenic

Ischemic heart disease

Electrocardiogram

Paraoxonase

Arsenic methyltransferase

Glutathione S-transferases omega

Drinking water

\begin{abstract}
A B S T R A C T
Arsenic has been linked to increased prevalence of cancer and cardiovascular disease (CVD), but the longterm impact of arsenic exposure remains unclear. Human paraoxonase (PON1) is a high-density lipoproteinassociated antioxidant enzyme which hydrolyzes oxidized lipids and is thought to be protective against atherosclerosis, but evidence remains limited to case-control studies. Only recently have genes encoding enzymes responsible for arsenic metabolism, such as AS3MT and GSTO, been cloned and characterized. This study was designed to evaluate the synergistic interaction of genetic factors and arsenic exposure on electrocardiogram abnormality. A total of 216 residents from three tap water implemented villages of previous arseniasis-hyperendemic regions in Taiwan were prospectively followed for an average of 8 years. For each resident, a 12-lead conventional electrocardiogram (ECG) was recorded and coded by Minnesota Code standard criteria. Eight functional polymorphisms of PON1, PON2, AS3MT, GSTO1, and GSTO2 were examined for genetic susceptibility to ECG abnormality. Among 42 incident cases with ECG deterioration identified among 121 baseline-normal subjects, arsenic exposure was significantly correlated with incidence of ECG abnormality. In addition, polymorphisms in two paraoxonase genes were also found associated with the incidence of ECG abnormality. A haplotype R-C-S constituted by polymorphisms of PON1 Q192R, -108C/T and PON2 C311S was linked to the increased risk. Subjects exposed to high levels of As (cumulative As exposure $>14.7$ ppm-year or drinking artesian well water $>21$ years) and carrying the R-C-S haplotype had significantly increased risks for ECG abnormality over those with only one risk factor. Results of this study showed a longterm arsenic effect on ECG abnormality and significant gene-gene and gene-environment interactions linked to the incidence of CVD. This finding might have important implications for a novel and potentially useful biomarker of arsenic risk.
\end{abstract}

(c) 2008 Elsevier Inc. All rights reserved.

\section{Introduction}

The dose-response relationship between arsenic and prevalence of cardiovascular diseases (CVD) has been documented including atherosclerosis, peripheral vascular disease (PVD), ischemic heart disease (IHD), hypertension, and cerebrovascular disease (Wang et al., 2007). For the general population of the southwestern coast of Taiwan, the major arsenic exposure source is contaminated groundwater. Residents used high-arsenic contaminated well water for drinking and cooking for many decades starting in the 1910s. A tap water supply system imple-

\footnotetext{
* Corresponding author. Division of Environmental Health and Occupational Medicine, National Health Research Institutes, 35, Keyan Road, Zhunan Town, Miaoli County 350, Taiwan. Fax: +886 037587406

E-mail address: slwang@nhri.org.tw (S.-L. Wang).
}

mented in the early 1960s ensured that artesian well water has not been used for drinking or cooking since the mid-1970s (Tseng, 1989).

A major cause of mortality worldwide, the estimated age-adjusted mortality for CVD in the U.S. is 152.1 per 100,000 (2002) and 48.3 per 100,000 in Taiwan (2005) (Department et al., 2005). Although both population-based and occupational studies have shown that longterm exposure to inorganic arsenic has significant toxic effect on the cardiovascular system, such that the maximum arsenic contamination level in drinking water was lowered from 0.05 to $0.01 \mathrm{ppm}$ by the U.S. Environmental Protection Agency in 2006, epidemiological evidence is still needed to develop regulatory guidelines (Smith et al., 2002; Navas-Acien et al., 2005).

The long-standing observation of individual variability in susceptibility to arsenic toxicity (NRC, 1999) may be partly due to differences in age, sex, and arsenic metabolism (Vahter, 2000; Watanabe et al., 
2001). Inter-individual differences in the speciation and amounts of arsenic metabolites have been reported among subjects chronically exposed to arsenic (Loffredo et al., 2003) and significant genetic determinants of arsenic metabolism is supported by epidemiologic evidence (Chung et al., 2002).

Only recently have genes encoding enzymes responsible for arsenic metabolism been cloned and characterized. These genes include AS3MT and GSTO. The AS3MT gene directly encodes a cytosolic enzyme, arsenic methyltransferase, which catalyzes the multi-step process to convert inorganic arsenic to monomethyl arsenical (MMA) and dimethyl arsenical (DMA) (Lin et al., 2002). Glutathione Stransferases (GSTs) are Phase II detoxification enzymes that catalyze the conjugation of reduced glutathione (GSH) to a wide variety of endogenous and exogenous electrophilic compounds (Townsend and Tew, 2003). A subfamily of GSTs, GST omega class, was shown to be identical with human monomethylarsonic acid $\left(\mathrm{MMA}^{\mathrm{V}}\right)$ reductase, the rate-limiting enzyme for biotransformation of inorganic arsenic. Polymorphisms of the GSTO genes have been shown to be associated with intracellular thiol status and the arsenic biotransformation efficiency of the cell (Tanaka-Kagawa et al., 2003).

High-density lipoprotein (HDL) is postulated to prevent the development of atherosclerosis by inhibiting the oxidation of low-density lipoprotein (LDL). Human paraoxonase (PON1) is a serum esterase/ lactonase transported on HDL particles and the major determinant of the antioxidant action of HDL (Aviram et al., 1998). Both in vitro and animal studies using PON1-knockout mice have shown that PON1 can prevent both HDL and LDL oxidation and is therefore a protective enzyme against development of atherosclerosis (Mackness et al., 1991; Watson et al., 1995; Shih et al., 1998).

Although the relationship between arsenic exposure and CVD has been reported, evidence of long-term influence of arsenic on the cardiovascular system is still limited. The main objective of this study was to investigate the possible contribution of genetic factors, including the PON1, AS3MT, and GSTO gene families, and long-term arsenic exposure to CVD after controlling for conventional risk factors.

\section{Methods}

Study area and population. The study area, described previously (Chen et al., 1985; Chen et al., 1995; Tseng et al., 2003), includes three arseniasis-hyperendemic villages, Homei, Fuhsin, and Hsinming in Putai Township on the southwestern coast of Taiwan. Residents in the study areas consumed high-arsenic contaminated well water for decades since the 1910s (Wu et al., 1961) because of the high salinity in shallow village wells. The arsenic concentration of artesian well water measured in the early 1960s was from 0.35 to $1.14 \mathrm{ppm}$, with a median of 0.78 ppm. (Chen et al., 1962; Kuo, 1964). An estimated total daily amount of arsenic ingested by local residents was as high as $1 \mathrm{mg}$, mainly from drinking water (Blackwell, 1961). A tap water supply system was implemented in the area in the early 1960s and the entire arseniasis-endemic area has been supplied with municipal water since the early 1970s. The arsenic concentration of tap water supplied in the study area was less than $0.01 \mathrm{ppm}$ (Chen and Chen, 1975). In 1993, 732 residents from the villages had a 12-lead baseline Electrocardiogram (ECG) recorded. In 2002, after an average follow-up period of 8 years, 216 of these participants provided a second ECG recording; 141 of them provided blood and urine specimens without an ECG recording; 229 were dead and their mortality determined through linkage with the national database; and the remaining 146 were lost to follow-up. Among the 121 residents with normal baseline ECGs, 42 developed an ECG abnormality at follow-up.

Data collection. At both baseline and follow-up, well trained public health nurses carried out standardized personal interviews based on a structured questionnaire to acquire demographic and socioeconomic characteristics, artesian well water usage, residential history, lifestyle variables, and personal and family history of hypertension, diabetes, and CVD. Cumulative arsenic exposure (in ppm-years) was calculated from the arsenic concentration in artesian well water (ppm) multiplied by duration of consuming artesian well water (years). The Human Ethical Committee of the National Health Research Institutes in Taiwan approved the study protocol which was based on the ethical standards formulated from the Helsinki Declarations of 1964 and revised in 2000 (World Medical Association, 2000). Informed consent was obtained from each participant before starting the study.

Physiological evaluation. Twelve-lead conventional ECG recording was conducted at the Beimen Branch, Shinyin Hospital. Minnesota standardized code classification (Prineas et al., 1982) was performed for both baseline and follow-up ECG readings at Epidemiological Cardiology Research Center (EPICARE), Department of Public Health Sciences, Wake Forest University School of Medicine, Winston-Salem, North Carolina, USA (blinded to all other study data). ECG readings were classified into normal and abnormal (including minor and major abnormality) according to the definition of cardiac function by myocardial infarction or ischemia ( $Q$ wave and STT change) (MC_1, MC_4, MC_5, MC_92), conduction defect (MC_7), arrhythmias (MC_6, MC_81-MC_88), atrial enlargement or ventricular hypertrophy (LVH_MC3/LVH_CV), and prolonged ventricular repolarization. Fasting plasma was analyzed for blood glucose, cholesterol, triglycerides, high- and low-density lipoproteins, and urine acid by Beckmen SYNCHRON LX20 System (Beckman Coulter, Fullerton, CA).

SNP selection and genotyping. We genotyped eight functional polymorphisms: C-108T (promoter), L55M (exon 3) and Q192R (exon 6) of PON1; A148G (exon 5) and C311S (exon 9) of PON2; M287T (exon 9) of AS3MT; A140D (exon 4) of GSTO1; and N142D (exon 5) of GSTO2. SNPs were selected from NCBI's SNP database based on prior implication in disease and minor allele frequency. Genomic DNA was extracted from whole blood using standard techniques. The AS3MT M287T polymorphism was determined using a commercially designed TaqMan SNP Genotyping Assay (Applied Biosystems, Foster City, CA). All other genotypes were conducted by PCR amplification followed by polymorphism-specific restriction enzyme digestion and gel analysis.

Statistical analysis. Differences in cardiovascular risk factors between ECG normal and abnormal subjects were assessed. Continuous variables were expressed as mean \pm standard deviation (SD) and evaluated by Student's $t$ or Wilcoxon rank-sum test. Categorical variables were expressed as proportions and compared using chi-square test or Fisher's exact test. Allele frequencies, genotype frequencies, and Hardy-Weinberg equilibrium were assessed separately in ECG abnormal and normal groups using SAS-genetics package. Relative distribution of polymorphisms in the ECG abnormal and ECG normal groups was assessed by chi-square analyses. Linkage disequilibrium (LD) as measured by D' was assessed using Haploview 4.0 (http:// www.broad.mit.edu/mpg/haploview/). Haplotypes and tag-SNPs were inferred using SAS. Logistic regression analysis was used to assess the effect of cardiovascular risk factors and genetic polymorphisms in relation to ECG abnormality. A $p$-value $<0.05$ was considered statistically significant. Permutation test, a significance test used to obtain the unknown reference distribution by calculating all possible values of the test statistic under random rearrangements of the disease status on the observed study subjects, was used to control for type 1 error for multiple testing due to the limited sample size, and the empirical $p$-values were reported (Potter, 2005). Statistical analyses were conducted using SAS version 9.1 (SAS, Inc., Cary, NC).

\section{Results}

Baseline characteristics of arsenic exposure and cardiovascular risk factors among study subjects are summarized in Table 1. A total 
Table 1

Baseline characteristics of arsenic and CVD risk factors among baseline-normal study participants classified by ECG status at follow-up

\begin{tabular}{lccc}
\hline Variable & $\begin{array}{c}\text { ECG normal } \\
(n=79)\end{array}$ & $\begin{array}{l}\text { ECG abnormal } \\
(n=42)\end{array}$ & $P$-value \\
& $62.0 \pm 7.3$ & $64.9 \pm 8.7$ & 0.058 \\
\hline Age (years) & $29(36.7)$ & $18(42.9)$ & 0.509 \\
Male (\%) & $14(17.7)$ & $13(31.0)$ & 0.082 \\
$\quad$ Cigarette Smoking (\%) & $10(12.7)$ & $6(14.3)$ & 0.801 \\
Alcohol consumption (\%) & $41.5 \pm 12.4$ & $43.3 \pm 14.3$ & 0.495 \\
Residency (years) & $19.2 \pm 9.3$ & $25.1 \pm 9.7$ & 0.004 \\
Drinking artesian water (years) & $13.6 \pm 8.4$ & $18.0 \pm 8.4$ & 0.030 \\
Cumulative as exposure (ppm-years) & $24.9 \pm 3.13$ & $24.5 \pm 3.4$ & 0.583 \\
BMI (kg/m $\left.{ }^{2}\right)$ & $113.1 \pm 64.7$ & $132.3 \pm 106.9$ & 0.296 \\
Triglycerides (mg/dl) & $220.2 \pm 45.0$ & $211.7 \pm 42.5$ & 0.323 \\
Total cholesterol (mg/dl) & $60.3 \pm 18.1$ & $59.2 \pm 14.3$ & 0.734 \\
HDL (mg/dl) & $121.9 \pm 48.1$ & $124.6 \pm 76.3$ & 0.833 \\
LDL (mg/dl) & $4.0 \pm 1.6$ & $3.8 \pm 1.2$ & 0.398 \\
Cholesterol/HDL ratio & $6.1 \pm 1.9$ & $5.7 \pm 1.8$ & 0.220 \\
Uric acid (mg/dl) & $124.8 \pm 19.3$ & $128.2 \pm 17.3$ & 0.345 \\
SBP (mm Hg) & $82.2 \pm 11.1$ & $84.2 \pm 8.6$ & 0.366 \\
DBP (mm Hg) & $98.6 \pm 23.1$ & $104.4 \pm 37.3$ & 0.307 \\
AC glucose (mg/dl) & $127.3 \pm 52.2$ & $129.1 \pm 78.1$ & 0.896 \\
PC glucose (mg/dl) & & &
\end{tabular}

Data are reported as mean \pm SD or counts (\%).

HDL: high-density lipoprotein; LDL: low-density lipoprotein; SBP: systolic blood pressure; DBP: diastolic blood pressure, AC: ante cibum, PC: post cibum.

of 42 incident cases among the 121 baseline-normal study subjects showed ECG deterioration at follow-up. Compared to ECG normal subjects, those with an ECG abnormality had significantly higher arsenic exposure as shown by both years of drinking artesian water $(p$-value $=0.004)$ and cumulative arsenic exposure index $(p$-value $=0.030)$. Age and proportion of cigarette smoking in the

Table 2

Association of SNPs and Hardy-Weinberg equilibrium test

\begin{tabular}{|c|c|c|c|c|c|c|}
\hline \multirow[t]{2}{*}{ Gene } & \multirow[t]{2}{*}{ SNP } & \multicolumn{2}{|c|}{ ECG status } & \multirow[t]{2}{*}{ OR $(95 \% \mathrm{CI})$} & \multicolumn{2}{|l|}{$P$-value } \\
\hline & & Normal & Abnormal & & Association & HWE \\
\hline \multirow[t]{12}{*}{$\overline{\text { PON1 }}$} & Q192R & & & & 0.175 & 0.916 \\
\hline & RR & 18 & 14 & 1.00 (reference) & & \\
\hline & $\mathrm{QR}$ & 27 & 9 & $0.43(0.15-1.20)$ & & \\
\hline & QQ & 11 & 3 & $0.35(0.08-1.50)$ & & \\
\hline & L55M & & & & 0.495 & 0.818 \\
\hline & LL & 48 & 21 & 1.00 (reference) & & \\
\hline & LM & 14 & 4 & $0.65(0.19-2.22)$ & & \\
\hline & MM & 0 & 0 & - & & \\
\hline & C-108T & & & & 0.643 & 0.528 \\
\hline & $\mathrm{CC}$ & 17 & 7 & 1.00 (reference) & & \\
\hline & $\mathrm{CT}$ & 30 & 15 & $1.21(0.41-3.56)$ & & \\
\hline & TT & 15 & 6 & $0.97(0.27-3.54)$ & & \\
\hline \multirow[t]{8}{*}{ PON2 } & C311S & & & & 0.318 & 0.853 \\
\hline & SS & 31 & 18 & 1.00 (reference) & & \\
\hline & CS & 24 & 7 & $0.50(0.18-1.40)$ & & \\
\hline & $\mathrm{CC}$ & 2 & 2 & $1.72(0.22-13.30)$ & & \\
\hline & A148G & & & & 0.709 & 0.551 \\
\hline & AA & 30 & 15 & 1.00 (reference) & & \\
\hline & AG & 28 & 10 & $0.71(0.28-1.85)$ & & \\
\hline & GG & 3 & 2 & $1.33(0.20-8.86)$ & & \\
\hline \multirow[t]{4}{*}{ AS3MT } & M287T & & & & 0.929 & 0.003 \\
\hline & MM & 67 & 30 & 1.00 (reference) & & \\
\hline & MT & 2 & 1 & $1.12(0.10-12.80)$ & & \\
\hline & $\mathrm{TT}$ & 0 & 0 & - & & \\
\hline \multirow[t]{4}{*}{ GSTO1 } & A140D & & & & 0.877 & 0.374 \\
\hline & AA & 41 & 21 & 1.00 (reference) & & \\
\hline & $A D$ & 22 & 9 & $0.80(0.31-2.04)$ & & \\
\hline & DD & 5 & 2 & $0.78(0.14-4.37)$ & & \\
\hline \multirow[t]{4}{*}{ GSTO2 } & N142D & & & & 0.995 & 0.413 \\
\hline & NN & 35 & 16 & 1.00 (reference) & & \\
\hline & ND & 30 & 14 & $1.02(0.43-2.43)$ & & \\
\hline & DD & 4 & 2 & $1.09(0.18-6.60)$ & & \\
\hline
\end{tabular}

Hardy-Weinberg Equilibrium (HWE) test was conducted among population including both ECG normal and abnormal subjects.
ECG abnormal group tended to be higher but did not reach statistical significance ( $p$-value $=0.058$ and 0.082 , respectively). No differences were observed in other cardiovascular risk factors including gender, alcohol consumption, BMI, serum lipids, blood pressure, and plasma glucose.

\section{Univariate SNP association analysis}

Eight functional polymorphisms: C-108T, L55M and Q192R of PON1, A148G and C311S of PON2, M287T of AS3MT, A140D of GSTO1, and N142D of GSTO2 were screened for association with ECG abnormality and Hardy-Weinberg equilibrium (HWE). None reached statistical significance, suggesting no univariate SNP association in the analysis. Genotypic frequencies of M287T showed a significant departure from HWE ( $p$-value $=0.003$ ) but because of the limited number of participants carrying the $\mathrm{T}$ alleles in this study population, they were excluded from subsequent analysis (Table 2).

Fig. 1 shows the related position and linkage disequilibrium (LD) between SNPs in the PON and GSTO gene clusters. Two SNPs within PON2 (C311S and A148G) and GSTO1-A140D and GSTO2-N142 were in high LD but SNPs within PON1 or adjacent SNPs between PON1 and PON2 (C-108T and C311S) had low LD measurements, implying they were not in the same LD block. Q192R, C-108T, C311S and A140D were identified as tag-SNPs.

$7 q 21.3$

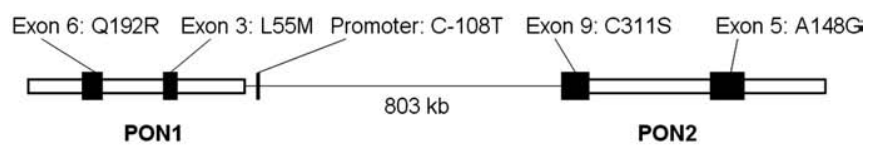

$10 \mathrm{q} 24.32$

$10 \mathrm{q} 25.1$
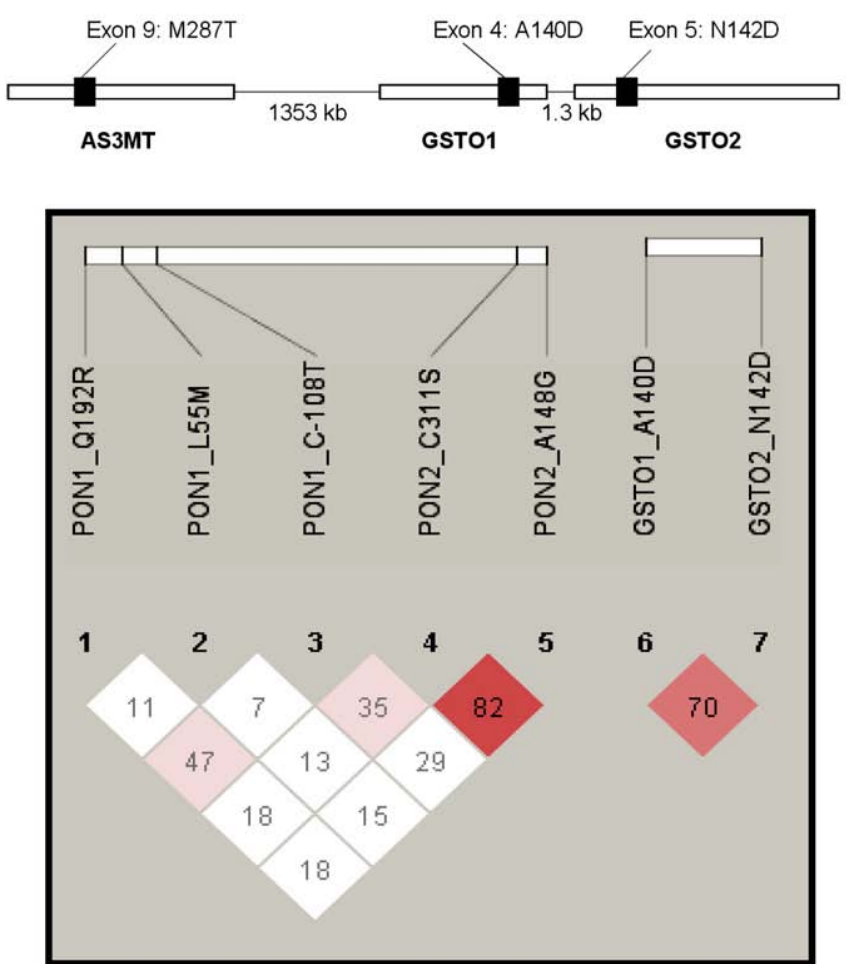

Fig. 1. Linkage disequilibrium (LD) plot of PON1 and GSTO gene clusters in 121 study subjects. The measure of LD (D') among all possible pairs of SNPs is shown graphically. Dark red represents high D' while white represents low D'. (For interpretation of the references to colour in this figure legend, the reader is referred to the web version of this article.) 
Table 3

Estimated haplotype frequencies and haplotypes association analysis with ECG abnormality

\begin{tabular}{|c|c|c|c|c|c|c|c|}
\hline Haplotypes & & & ECG normal & ECG abnormal & OR & $P$-value ${ }^{\mathrm{a}}$ & $P$-value ${ }^{b}$ \\
\hline Q192R & L55M & C-108T & & & & & 0.239 \\
\hline $\mathrm{R}$ & $\mathrm{L}$ & $\mathrm{T}$ & $46(37.1 \%)$ & $24(42.9 \%)$ & 1.00 (reference) & & \\
\hline Q & $\mathrm{L}$ & $\mathrm{C}$ & $38(30.7 \%)$ & $10(17.9 \%)$ & $0.50(0.22-1.18)$ & 0.087 & \\
\hline $\mathrm{R}$ & $\mathrm{L}$ & $\mathrm{C}$ & $18(14.5 \%)$ & $15(26.8 \%)$ & $1.60(0.69-372)$ & 0.312 & \\
\hline $\mathrm{Q}$ & M & $\mathrm{C}$ & $8(6.5 \%)$ & $4(7.1 \%)$ & $0.96(0.26-3.51)$ & 0.933 & \\
\hline Q & $\mathrm{L}$ & $\mathrm{T}$ & $8(6.5 \%)$ & $3(5.4 \%)$ & $0.72(0.17-2.96)$ & 0.663 & \\
\hline Q192R & C-108T & & & & & & 0.206 \\
\hline $\mathrm{R}$ & $\mathrm{T}$ & & $52(41.9 \%)$ & $24(42.9 \%)$ & 1.00 (reference) & & \\
\hline Q & C & & $46(37.1 \%)$ & $14(25.0 \%)$ & $0.66(0.31-1.42)$ & 0.266 & \\
\hline $\mathrm{R}$ & $\mathrm{C}$ & & $18(14.5 \%)$ & $15(26.8 \%)$ & $1.81(0.78-4.18)$ & 0.187 & \\
\hline Q & $\mathrm{T}$ & & $8(6.5 \%)$ & $3(5.4 \%)$ & $0.81(0.20-3.33)$ & 0.772 & \\
\hline C311S & A148G & & & & & & 0.340 \\
\hline $\mathrm{S}$ & A & & 89 (71.8\%) & $40(70.4 \%)$ & 1.00 (reference) & & \\
\hline C & G & & $32(25.8 \%)$ & $10(17.9 \%)$ & $0.70(0.31-1.56)$ & 0.340 & \\
\hline A140D & N142D & & & & & & 0.427 \\
\hline A & $\mathrm{N}$ & & $96(69.5 \%)$ & $43(67.2 \%)$ & 1.00 (reference) & & \\
\hline D & $\mathrm{D}$ & & $28(20.3 \%)$ & $10(15.6 \%)$ & $0.80(0.36-1.77)$ & 0.572 & \\
\hline A & $\mathrm{D}$ & & $10(7.3 \%)$ & $8(12.5 \%)$ & $1.79(0.66-4.84)$ & 0.250 & \\
\hline Q192R & C-108T & C311S & & & & & 0.370 \\
\hline $\mathrm{R}$ & $\mathrm{T}$ & $\mathrm{S}$ & 47 (37.9\%) & $21(37.5 \%)$ & 1.00 (reference) & & \\
\hline Q & $\mathrm{C}$ & $\mathrm{S}$ & 27 (21.7\%) & $9(16.1 \%)$ & $0.75(0.30-1.86)$ & 0.500 & \\
\hline $\mathrm{R}$ & C & $\mathrm{S}$ & $14(11.3 \%)$ & $12(21.4)$ & $1.92(0.76-4.85)$ & 0.157 & \\
\hline $\mathrm{Q}$ & $\mathrm{C}$ & C & $19(15.3 \%)$ & $5(8.9 \%)$ & $0.59(0.19-1.79)$ & 0.348 & \\
\hline $\mathrm{Q}$ & $\mathrm{T}$ & $\mathrm{S}$ & $8(6.5 \%)$ & $3(5.4 \%)$ & $0.84(0.20-3.48)$ & 0.803 & \\
\hline
\end{tabular}

Haplotypes with a frequency less than $5 \%$ were removed.

Empirical P-values: ${ }^{\mathrm{a}}$ Haplotype-specific test, ${ }^{\text {b }}$ Haplotype-global test.

\section{Haplotype analysis and association with ECG abnormality}

Haplotypes of PON1, PON2, GSTO1, GSTO2 and tag-SNPs of the PON gene cluster were constructed, and those whose frequencies were $<5 \%$ were excluded from association analysis (Table 3). Overall, the effects of these haplotypes on ECG abnormality were not statistically significant after 10,000 permutations; however, the haplotype R-C-S constructed by Q192R, C-108T and C311S had the highest odds, 1.92 $(95 \%$ CI: 0.76-4.85, $p$-value $=0.157)$ times increased risk toward ECG abnormality.

The relative odds of lipid profiles for PON-haplotype R-C-S carrier compared with non-carriers are shown in Fig. 2. The R-C-S haplotype was positively correlated with higher serum HDL-cholesterol, LDLcholesterol, and triglyceride levels without statistical significance, but was significantly associated with increased total cholesterol levels $(\mathrm{OR}=2.91,95 \% \mathrm{CI}: 1.13-7.70, p$-value $=0.028)$.

Synergistic association of PON haplotype and arsenic on ECG abnormality

The synergistic associations between PON haplotype and arsenic exposure are summarized in Tables 4a, 4b. The PON R-C-S haplotype

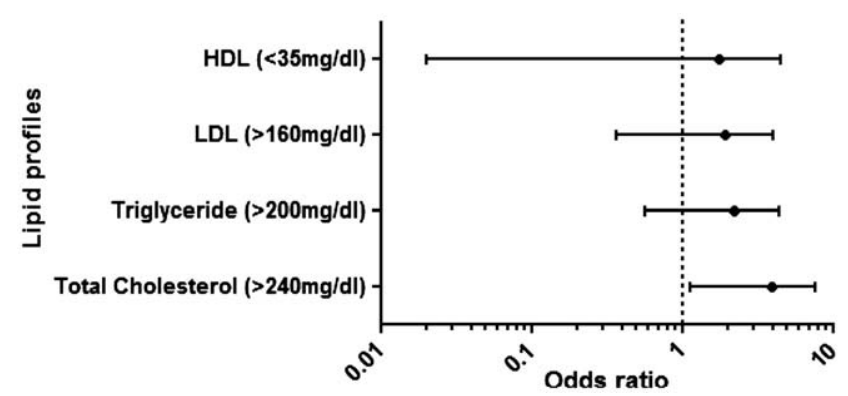

Fig. 2. Odds ratios of ECG abnormality and lipid profiles for Q192R, C-108T and C311S R-C-S haplotype carrier among study subjects $(N=121)$. carrier with higher cumulative arsenic exposure (greater than the median value of 14.7 ppm-years) showed a $>14.66$ (95\% CI: $1.83-$ $117.64, p$-value $=0.022$ ) increased risk for ECG abnormality compared to non-RCS haplotype carriers with low cumulative arsenic exposure (<14.7 ppm-years) (Table 4a). The PON R-C-S haplotype carrier with more years of drinking artesian water (greater than the median of 21 years) had a 10.83 -fold $(95 \% \mathrm{CI}$ : $1.83-64.03, p$-value $=0.030)$ increased risk (Table $4 \mathrm{~b})$. These associations were even stronger after adjusting for age, gender, and cigarette smoking, when the odds increased to 19.19 (95\% CI: 1.86-197.76, $p$-value $=0.014$ ) and 21.09 (95\% CI: 2.77-160.35, $p$-value $=0.010)$ for cumulative exposure index and drinking years, respectively.

\section{Discussion}

We showed that previous arsenic exposure was linked to incidence of cardiovascular disease (reflected in the development of ECG abnormalities) even decades after cessation of arsenic-contaminated water consumption, suggesting latent arsenic damage even after exposure was removed. However, no significant association with ECG abnormality was found for conventional cardiovascular risk factors such as gender, alcohol consumption, BMI, lipid profiles, blood pressure, and plasma glucose.

Although the association between ECG abnormality and any single SNP or haplotype did not reach statistical significance, the R192 and $-108 \mathrm{C}$ alleles were correlated with increased risk. Participants who carried both R192 and -108C alleles had a 1.81-fold increased risk, and carrying R192, -108C, and S311 alleles gave a 1.92-fold increased risk. When arsenic exposure history was taken into consideration, a significant gene-environment synergistic effect between the PON haplotype and arsenic was noted. Residents who carried the high risk RCS haplotype and had high chronic arsenic exposure were at a much greater risk than those with one risk factor only (Tables 4a, 4b).

Many studies have investigated the relationship of PON1 to coronary heart disease (CHD) or myocardial infarction (MI) and an overall conclusion from a large meta-analysis of 43 studies showed a 
Table 4a

Synergistic effects of Q192R, C-108T, and C311S R-C-S haplotype carrier and high cumulative arsenic exposure (CAE) (>median of 14.7 ppm-years) on ECG abnormality

\begin{tabular}{|c|c|c|c|c|c|c|c|}
\hline $\mathrm{R}-\mathrm{C}-\mathrm{S}$ & CAE & $\begin{array}{l}\text { ECG } \\
\text { normal }\end{array}$ & $\begin{array}{l}\text { ECG } \\
\text { abnormal }\end{array}$ & OR $(95 \% \mathrm{CI})$ & $P$-value & OR $(95 \% C I)^{a}$ & $\begin{array}{l}\text { Empirical } \\
P \text {-value }\end{array}$ \\
\hline- & - & 22 & 3 & 1.00 (reference) & - & 1.00 (reference) & - \\
\hline+ & - & 8 & 2 & $1.83(0.26-13.06)$ & 0.369 & $1.57(0.19-13.00)$ & 0.319 \\
\hline- & + & 17 & 11 & $4.74(1.14-19.72)$ & 0.452 & $4.27(0.83-22.08)$ & 0.632 \\
\hline+ & + & 2 & 4 & $14.66(1.83-117.64)$ & 0.022 & 19.19 (1.86-197.76) & 0.014 \\
\hline
\end{tabular}

CAE: cumulative arsenic exposure (ppm-years).

R-C-S: Q192R, C-108T and C311S R-C-S haplotype.

a Permutation analysis adjusted by age, gender, and cigarette smoking.

1.12-fold increased risk of the R192 allele for CHD (Wheeler et al., 2004). No significant overall association was found for the $-108 \mathrm{C}$ and the S311 allele. Functionally, the R192 allele is known to be associated with fast catalytic rate toward hydrolyzing paraoxon, a non-physiological surrogate substrate used to measure PON1 enzymatic activity (Furlong et al., 2002). On the other hand, the fact that the R192 allele had less ability of hydrolyzing oxidized lipids (Aviram et al., 2000) and lactones (Billecke et al., 2000) than the Q192 allele may explain why the R192 allele is the risk allele for CHD. The promoter region polymorphism $-108 \mathrm{C} / \mathrm{T}$ has effects on PON1 expression, with the C allele associated with increased level of serum PON1 (Furlong et al., 2002). No functional effects have been reported for the PON2 C311S polymorphism. Our results of the RCS haplotype linked to increased risk agree with the previous findings of the R192 allele but is somewhat contradictory to the functional implication of the $-108 \mathrm{C} / \mathrm{T}$ polymorphism, as the $\mathrm{C}$ allele is more likely a protective rather than a risk factor. Whether the existence of the $C$ allele in the risk haplotype is of any biological significance or only a genetic linkage to the other two alleles remains to be studied.

It has been argued whether serum PON1 activity is a better predictor for cardiovascular disease than is PON1 genotype (Jarvik et al., 2000; Mackness et al., 2003; Bhattacharyya et al., 2008). In this study, subjects who carry the risk haplotype RCS, had significantly higher serum PON1 activity compared to non-carriers (1071.3 \pm 308.1 vs. $746.5 \pm 401.0, p<0.001)$. However, we found no significant differences in serum PON1 activity between ECG normal and abnormal subjects (788.3 \pm 394.3 vs. $924.5 \pm 473.5, p=0.112)$. We must point out that serum PON1 activity was measured at the end of follow-up, i.e., the second time of ECG measurement, and no baseline data of PON1 activity was available. Therefore, given the small sample size and no baseline data, it is difficult to draw any conclusion whether PON1 activity also plays a role in arsenic-related ECG abnormality.

Low follow-up rates and limited number of cases were the major limitations in our study. We overcame the difficulty of small sample size by using permutation test. Permutation test is a non-parametric approach and has been used to obtain the empirical $p$-value through simulation by resampling study subjects. If the disease status is exchangeable under the null hypothesis, then the resulting tests will yield exact significance levels when the original distribution is unknown or size is relatively small. Because arsenic exposure is known to be atherogenic and carcinogenic (Chen and Lin, 1994), possible selective survival in this cohort may bias our findings. The cumulative arsenic exposure among subjects with ECG measurements was significantly lower compared to those who were lost to ECG measurements $(19.0 \pm 11.7$ vs. $25.0 \pm 14.9, p<0.001)$ and therefore, an underestimate of arsenic risk for CVD is possible. Nevertheless, we still found a significant relationship between arsenic and ECG abnormality given the low follow-up rate and effect size, indicating that the longterm effect of arsenic on CVD is a true rather than a false-positive finding. On the other hand, we found no differences in genetic frequencies of PON1 and PON2 polymorphisms between the ECG measurement group and the loss-to-follow-up group (as shown in Supplement Table 1), suggesting no selective bias between the two groups in terms of PON genotype distribution. Thus, our finding of the RCS haplotype as the risk group should hold up.

ECG abnormality with the Minnesota standardized code classification has long been used as standard clinical diagnosis for MI or ischemic heart disease. However, it could only be used as an index of preclinical CVD in this study because the subtype regarding abnormal reading was not specified. Clinical heterogeneity may dismiss this finding when different pathological stages of CVD were considered. Moreover, we conducted only two ECG screenings (one at baseline and the other at the end of follow-up) rather than repeated measures during the study period, making it difficult to infer the incident time of disease occurrence. There were no supplementary screening tools for CVD or disease history other than ECG; however, we obtained similar results for ischemic heart disease diagnosis using the ECG coding (data not shown). Of 42 ECG abnormal cases, 31 were categorized into myocardial infarction and ischemic heart disease, indicating a homogeneous etiology among cases.

Another limitation of the present study was the method of arsenic exposure assessment. We used median arsenic concentration in artesian wells shared by residents to represent arsenic exposure level. Butai is a relatively small town in Taiwan whose residents shared common artesian well water close to their living or working areas. Most underground wells were sealed and arsenic-contaminated water no longer used for drinking or cooking after tap water system implementation in the mid-1970s. We believe our measurements provide a reasonable estimate of arsenic exposure history.

In conclusion, our study demonstrated significant synergistic effects of common genetic variations in the PON gene cluster and arsenic exposure on incidence of ECG abnormality among Taiwanese with previous exposure to high-level arsenic, when other conventional risk factors were considered. This finding might have important implications for a novel and potentially useful biomarker of arsenic risk. Biological mechanisms of gene-gene and gene-environment interactions should be considered likely subjects for future investigations.

Table 4b

Synergistic effects of Q192R, C-108T, and C311S R-C-S haplotype carrier and more years of drinking artesian water (DAW) (>mean of 21 years) on ECG abnormality

\begin{tabular}{|c|c|c|c|c|c|c|c|}
\hline R-C-S & DAW & ECG normal & ECG abnormal & OR $(95 \% \mathrm{CI})$ & $P$-value & OR $(95 \% \mathrm{CI})^{\mathrm{a}}$ & Empirical $P$-value \\
\hline- & - & 26 & 3 & 1.00 (reference) & - & 1.00 (reference) & - \\
\hline+ & - & 8 & 2 & $2.17(0.31-15.33)$ & 0.404 & $1.90(0.24-14.94)$ & 0.190 \\
\hline- & + & 19 & 15 & $6.84(1.73-27.02)$ & 0.101 & $10.66(2.12-53.55)$ & 0.055 \\
\hline+ & + & 4 & 5 & $10.83(1.83-64.03)$ & 0.030 & $21.09(2.77-160.35)$ & 0.010 \\
\hline
\end{tabular}

DAW: drinking artesian water (years).

RCS: Q192R, C-108T and C311S R-C-S haplotype.

a Permutation analysis adjusted by age, gender, and cigarette smoking. 


\section{Conflict of interest statement}

The authors declare that they have no competing interests.

\section{Acknowledgments}

This study was financially supported by research grants from the National Health Research Institute (EO-094-PP-11, EO-095-PP-07, EO-096-PP-07). We are greatly indebted to the clinicians and nurses at Hsin-Ying Branch Hospital, Beimen, Tainan for their support in subjects' physical examinations. We are grateful to Ms. Hsiao-Yen Chen for her assistance in data collection and management.

\section{Appendix A. Supplementary data}

Supplementary data associated with this article can be found, in the online version, at doi:10.1016/j.taap.2008.12.017.

\section{References}

Aviram, M., Rosenblat, M., Bisgaier, C.L., Newton, R.S., Primo-Parmo, S.L., La Du, B.N., 1998. Paraoxonase inhibits high-density lipoprotein oxidation and preserves its functions. A possible peroxidative role for paraoxonase. J. Clin. Invest. 101, 1581-1590.

Aviram, M., Hardak, E., Vaya, J., Mahmood, S., Milo, S., Hoffman, A., Billicke, S., Draganov, D., Rosenblat, M., 2000. Human serum paraoxonases (PON1) Q and R selectively decrease lipid peroxides in human coronary and carotid atherosclerotic lesions: PON1 esterase and peroxidase-like activities. Circulation 101, 2510-2517.

Bhattacharyya, T., Nicholls, S.J., Topol, E.J., Zhang, R., Yang, X., Schmitt, D., Fu, X., Shao, M. Brennan, D.M., Ellis, S.G., Brennan, M.L., Allayee, H., Lusis, A.J., Hazen, S.L., 2008. Relationship of paraoxonase 1 (PON1) gene polymorphisms and functional activity with systemic oxidative stress and cardiovascular risk. JAMA 299, 1265-1276.

Billecke, S., Draganov, D., Counsell, R., Stetson, P., Watson, C., Hsu, C., La Du, B.N., 2000. Human serum paraoxonase (PON1) isozymes $Q$ and $R$ hydrolyze lactones and cyclic carbonate esters. Drug Metab. Dispos. 28, 1335-1342.

Blackwell, R.Q., 1961. Estimation total arsenic ingested by residents in the endemic blackfoot area. J. Formosan. Med. Assoc. 60, 1143-1144.

Chen, W.Y., Chen, K.P., 1975. Study on arsenic artesian well water and blackfoot disease progress. In Taichung, Taiwan: Taiwan Provincial Institute of Environmental Sanitation. Taiwan Provincial Institute of Environmental Sanitation, Taichung, Taiwan.

Chen, C.J., Lin, L.J., 1994. Human carcinogenicity and atherogenicity induced by chronic exposure to inorganic arsenic. In: Nriagu, J.O. (Ed.), Progress in Arsenic in the Environment, Part II. Human Health and Ecosystem Effects, Wiley, New York.

Chen, K.P., Wu, T.C., Wu, T.C., 1962. Epidemiologic studies on blackfoot disease in Taiwan. 3. Physicochemical characteristics of drinking water in endemic blackfoot disease areas. Memoirs of College of Medicine (National Taiwan University) 8, 115-129.

Chen, C.J., Chuang, Y.C., Lin, T.M., Wu, H.Y., 1985. Malignant neoplasms among residents of a blackfoot disease-endemic area in Taiwan: high-arsenic artesian well water and cancers. Cancer Res. 45, 5895-5899.

Chen, C.J., Hsueh, Y.M., Lai, M.S., Shyu, M.P., Chen, S.Y., Wu, M.M., Kuo, T.L., Tai, T.Y., 1995 Increased prevalence of hypertension and long-term arsenic exposure. Hypertension 25, 53-60.

Chung, J.S., Kalman, D.A., Moore, L.E., Kosnett, M. Arroyo, A.P., Beeris, M., Mazumder, D. N., Hernandez, A.L., Smith, A.H., 2002. Family correlations of arsenic methylation patterns in children and parents exposed to high concentrations of arsenic in drinking water. Environ. Health Perspect. 110, 729-733.

Department of Health, Executive Yuan (Taiwan) R. O. C. (2005). Health and Vital statistics-Vital Statistics.
Furlong, C.E., Cole, T.B., Jarvik, G.P., Costa, L.G., 2002. Pharmacogenomic considerations of the paraoxonase polymorphisms. Pharmacogenomics 3, 341-348.

Jarvik, G.P., Rozek, L.S., Brophy, V.H., Hatsukami, T.S., Richter, R.J., Schellenberg, G.D. Furlong, C.E., 2000. Paraoxonase (PON1) phenotype is a better predictor of vascular disease than is PON1(192) or PON1(55) genotype. Arterioscler. Thromb. Vasc. Biol. 20, 2441-2447.

Kuo, T. L. (1964). Arsenic Content of Artesian Well Water in Endemic Area of Chronic Arsenic Poisoning In Institute of Pathology, pp. 7-13. National Taiwan University.

Lin, S., Shi, Q., Nix, F.B., Styblo, M., Beck, M.A., Herbin-Davis, K.M., Hall, L.L., Simeonsson, J.B., Thomas, D.J., 2002. A novel S-adenosyl-L-methionine:arsenic(III) methyltransferase from rat liver cytosol. J. Biol. Chem. 277, 10795-10803.

Loffredo, C.A., Aposhian, H.V., Cebrian, M.E., Yamauchi, H., Silbergeld, E.K., 2003. Variability in human metabolism of arsenic. Environ. Res. 92, 85-91.

Mackness, M.I., Arrol, S., Durrington, P.N., 1991. Paraoxonase prevents accumulation of lipoperoxides in low-density lipoprotein. FEBS Lett. 286, 152-154.

Mackness, B., Durrington, P., McElduff, P., Yarnell, J., Azam, N., Watt, M., Mackness, M., 2003. Low paraoxonase activity predicts coronary events in the Caerphilly Prospective Study. Circulation 107, 2775-2779.

Navas-Acien, A., Sharrett, A.R., Silbergeld, E.K., Schwartz, B.S., Nachman, K.E., Burke, T.A Guallar, E., 2005. Arsenic exposure and cardiovascular disease: a systematic review of the epidemiologic evidence. Am. J. Epidemiol. 162, 1037-1049.

NRC, 1999. Arsenic in Drinking Water. National Academy Press, Washington, DC

Potter, D.M., 2005. A permutation test for inference in logistic regression with smalland moderate-sized data sets. Stat. Med. 24, 693-708.

Prineas, R. J., Crow, R. S., and Blackburn, H. (1982). The Minnesota Code Manual of Electrocardiographic Findings. (John Wright PSB Inc., Ed.). MA, Boston.

Shih, D.M., Gu, L., Xia, Y.R., Navab, M., Li, W.F., Hama, S., Castellani, L.W., Furlong, C.E., Costa, L.G., Fogelman, A.M., Lusis, A.J., 1998. Mice lacking serum paraoxonase are susceptible to organophosphate toxicity and atherosclerosis. Nature 394, 284-287.

Smith, A.H., Lopipero, P.A., Bates, M.N., Steinmaus, C.M., 2002. Public health. Arsenic epidemiology and drinking water standards. Science 296, 2145-2146.

Tanaka-Kagawa, T., Jinno, H., Hasegawa, T., Makino, Y., Seko, Y., Hanioka, N., Ando, M. 2003. Functional characterization of two variant human GSTO 1-1s (Ala140Asp and Thr217Asn). Biochem. Biophys. Res. Commun. 301, 516-520.

Townsend, D., Tew, K., 2003. Cancer drugs, genetic variation and the glutathione-Stransferase gene family. Am. J. Pharmacogenomics 3, 157-172.

Tseng, W.P., 1989. Blackfoot disease in Taiwan: a 30-year follow-up study. Angiology 40 547-558.

Tseng, C.H., Chong, C.K., Tseng, C.P., Hsueh, Y.M., Chiou, H.Y., Tseng, C.C., Chen, C.J., 2003. Long-term arsenic exposure and ischemic heart disease in arseniasis-hyperendemic villages in Taiwan. Toxicol. Lett. 137, 15-21.

Vahter, M. (2000). Genetic polymorphism in the biotransformation of inorganic arsenic and its role in toxicity. Toxicol Lett 112-113, 209-217.

Wang, C.H., Hsiao, C.K., Chen, C.L., Hsu, L.I., Chiou, H.Y., Chen, S.Y., Hsueh, Y.M., Wu, M.M., Chen, C.J., 2007. A review of the epidemiologic literature on the role of environmental arsenic exposure and cardiovascular diseases. Toxicol. Appl. Pharmacol. 222, 315-326.

Watanabe, C., Inaoka, T., Kadono, T., Nagano, M., Nakamura, S., Ushijima, K., Murayama, N., Miyazaki, K., Ohtsuka, R., 2001. Males in rural Bangladeshi communities are more susceptible to chronic arsenic poisoning than females: analyses based on urinary arsenic. Environ. Health Perspect. 109, 1265-1270.

Watson, A.D., Berliner, J.A., Hama, S.Y., La Du, B.N., Faull, K.F., Fogelman, A.M., Navab, M., 1995. Protective effect of high density lipoprotein associated paraoxonase. Inhibition of the biological activity of minimally oxidized low density lipoprotein. J. Clin. Invest. 96, 2882-2891.

Wheeler, J.G., Keavney, B.D., Watkins, H., Collins, R., Danesh, J., 2004. Four paraoxonase gene polymorphisms in 11212 cases of coronary heart disease and 12786 controls: meta-analysis of 43 studies. Lancet 363, 689-695.

World Medical Association (2000). Declaration of Helsinki: Ethical Principles for Medical Research Involving Human Subjects. In Bulletin of Medical Ethics pp. 8-11.

Wu, H.Y., Chen, K.P., Tseng, W.P., Hsu, C.L., 1961. Epidemiologic studies on blackfoot disease: prevalence and incidence of the disease by age, sex, year, occupation, and geographic distribution. Memoirs of College of Medicine (National Taiwan University) 7, 1-18. 